\title{
An Multi-objective Model of Order Allocation under Considering Disruption Risk and Scenario Analysis in a Supply Chain Environment
}

\author{
An Integrated Multi-objective Model for Order Allocation
}

\author{
Wei Pan* \\ Economics and Management School \\ Wuhan University \\ Wuhan, China \\ mrpanwei2000@163.com \\ *Corresponding author
}

\author{
Fengxia Wang \\ Economics and Management School \\ Wuhan University \\ Wuhan, China \\ mrpanwei2000@163.com
}

\begin{abstract}
Within a supply chain, order allocation plays a key role for procurement management. This paper researches a company can order crucial raw materials, for example crude oil, from multiple suppliers. At the same time, order allocation is an important multiple criteria decision making problem including cost, disruption risk, quality and service etc. We wish the total purchasing cost is minimized, and we can gain a high service quality. Meanwhile, we defined different disruption penalty function in three scenarios. Finally, we have developed an integrated multi-objective decision model to optimize order allocation.
\end{abstract}

Keywords-order allocation; supply chain; purchasing cost; disruption risk

\section{INTRODUCTION}

Order allocation problem includes how one company should determine order quantities in many potential candidates. Today enterprises face more and more tremendous competitive pressures and challenge, purchasing cost is a significant factor of affecting company competitive capability. In most industries the cost of raw materials and component parts constitutes the main cost of a product, particularly in some cases it can account for up to $70 \%$ (Ghobadian, 1993). In some high technology firms, purchased materials and services represent up to $80 \%$ of total product cost (Weber, 1991). In such environment, researchers and practitioners are more concerned about order allocation than before.

At the same time, order allocation is a multi-criteria decision making problem, which is affected by several conflicting factors including cost, quality, delivery and service etc. It is noted that multiple criteria usually are unequally important. Consequently a purchasing manager must analyze the trade off among the several criteria. At any time of an order, decisions have to be made by the company concerning the allocation of products to the suppliers and the respective order quantities, so that the total purchasing cost is minimized, while maintaining a specified service level. Current researchers have published some papers about order allocation process. Pan [2] proposed multiple sourcing for improving the reliability of supply for critical materials, in which more than one supplier is used and the demand is split between them. Most purchasing managers agree that buying from more than one vendor will protect the buying firm in the case of shortages. Narasimhan and Stoynoff [20] applied a single objective, mixed integer programming model to a large manufacturing firm in the Midwest, to optimize the allocation procurement for a group of vendors. The objective of this model is to minimize the sum of the shipping and the penalty costs. The model constraints are related to vendors' production capabilities and demand. Kingsman [7] stated that one of the most important problems which has received little attention from OR practitioners are the purchasing of materials whose prices are continually fluctuating in a stochastic manner over time. He discussed conceptually linear programming and dynamic programming as tools for purchasing raw materials with fluctuating prices. Yanga[25] studied a supplier selection problem, where a buyer, while facing random demand, is to decide ordering quantities from a set of suppliers with different yields and prices. They provided the mathematical formulation for the buyer's profit maximization problem and proposed a solution method based on a combination of the active set method and the Newton search procedure. Buffa and Jackson [6] presented a schedule purchase for a single product over a defined planning horizon via a goal programming model considering price, quality and delivery criteria. It included buyer's specification such as material requirement and safety stock. Basnet and Leung [5] balance ordering and holding costs in a multi-item model by considering a multi-period scheduling horizon. They proposed an uncapacitated mixed linear integer programming that minimizes the aggregate purchasing, ordering and holding costs subject to demand satisfaction. Syam Menon[23] developed a modal for allocating customer orders to machines so as to minimize the total cost of production. It can be formulated as a dual-angular integer program, with identical machines inducing symmetry to solve decomposable dual-angular integer programs and successfully applies it to solve the problem from the paper industry. Ezgi Aktar Demirtas [13] developed a multi-objective mixed integer linear programming (MOMILP) for order allocation. This modal is proposed to define the 
optimum quantities among the selected suppliers under deterministic constraint. Vaidyanathan Jayaraman [26] presented a comprehensive modal. The objective of the order allocation model minimized both fixed and variable cost over a given planning period. Xiangtong Qi[29] studied an integrated decision making model for a supply chain system where a manufacturer faced a price sensitive demand and multiple capacitated suppliers, two issues that were often considered separately in the literature. The goal was to maximize total profit by determining an optimal selling price and at the same time acquiring enough supplying capacity.

However, the past studies shown above have little literature under considering disruption risk. Ghodsypour [21] developed a mixed integer non-linear programming model to solve the multiple sourcing problem, which takes into account the total cost of logistics, including net price, storage, transportation and ordering costs. Buyer limitations on budget, quality, service, etc. can also be considered in the model.

Kelle[11] provided the optimal split in multi-sourcing frequently provides a lower stock-out risk if the variability of the lead-time demand is considerable. Smeltzer and Siferd [18] clearly pointed out that when an organization reduces its supplier base, it relies on fewer suppliers for critical materials, possibly increasing the risk of an interruption of supply. Ruengsak Kawtummachai [14] developed a solution algorithm and tested it to allocate order of products to the suppliers so that the total purchasing cost is minimized, while maintaining a specified service level. The problem of how to allocate orders to the proper suppliers tends to be an important topic, especially in case of the crude oil order allocation problem.

Therefore, in this paper, we have tried to construct a practical and meaningful method that will be used to allocate orders to the selected supplier in order to guarantee high steady supply levels. Our research is of value to both academics as well as practitioners. The factors that we have used to allocate the order consist of percentage of disruption risk and order price. We seek to examine the interactions between supply disruption mitigation and supply order cost, and to investigate the role of order allocation method in alleviating disruption risk. For this observation, we construct the integrated multiobjective decision model.

The remainder of this paper is organized as follows. Section 2 , this paper presents the integrated multi-objective decision model. Finally, we have made conclusions and future study.

\section{MODEL}

We use the following notations throughout this paper.

$D_{i r} \quad$ Demand for item i in the rth order

$V_{i j} \quad$ Capacity of the jth supplier for item $\mathrm{i}$

$X_{i j} \quad$ Order quantity supplied by supplier j for item i

$S_{j} \quad$ Supplier j $S_{j}=1$,if supplier $\mathrm{j}$ is selected for purchase;

otherwise $S_{j}=0$ )

$F\left(X_{i j}\right)$ Penalty function of $X_{i j}$ $q_{i j} \quad$ Quality rate for material i from jth supplier

$\mathrm{C}_{\mathrm{ij}}$ Unit cost for supplier $\mathrm{j}$ to supply item $\mathrm{i}$

$O_{\mathrm{ij}}$ Order cost for supplier j to supply material i

$W_{h}$ The weight of the hth objective

$\mathrm{Z}$ Objective function

Since disruption risk is unavoidable, a penalty function should be considered and defined. Notably, disruption usually causes loss to customers. Moreover, the more important materials is, the higher the penalty will be considered. According to this relationship, we assume that scenarios are divided into three conditions and accordingly three different penalty functions are defined as follows:

(1) When the missing materials can easily be purchased from others, the penalty function is equal to zero, i.e.,

$$
F\left(X_{i j}\right)=0
$$

(2) When the missing materials can be purchased from others, the penalty function is linear as follows:

$$
F\left(X_{i j}\right)=a_{i j} X_{i j}
$$

(3) When the missing materials can not be purchased from others, the penalty function is non-linear as follows:

$$
F\left(X_{i j}\right)=a_{i j} X_{i j}^{t}
$$

Objective functions

Cost - the sum of material cost, order cost and disruption loss should be minimized; therefore,

$\operatorname{Min} \mathrm{f} 1\left(X_{i j}\right)=\sum_{i=1}^{m} \sum_{j=1}^{n} \mathrm{X}_{\mathrm{ij}} C_{i j}+\sum_{j=1}^{n} \mathrm{O}_{\mathrm{ij}} \mathrm{S}_{\mathrm{j}}+\sum_{i=1}^{m} \sum_{j=1}^{n} d q_{\mathrm{ij}} F\left(X_{i j}\right)$

$\operatorname{Max} \mathrm{f} 2\left(X_{i j}\right)=\sum_{j=1}^{n} \mathrm{X}_{\mathrm{ij}} \mathrm{q}_{\mathrm{ij}}$

The overall purpose of AIMODMURC is to minimize the sum of the purchasing cost (supply disruption risk) and maximize item quality. Each goal has distinct weight in this modal; as a result, different weights will be attached to two goals.

The objective function of the modal is:

$$
\begin{aligned}
& \mathrm{Z}=\mathrm{W}_{1} \min \mathrm{f} 1\left(X_{i j}\right)+\mathrm{W}_{2} \max \mathrm{f} 2\left(X_{i j}\right) \\
& =\mathrm{W}_{1} \min \left(\sum_{i=1}^{m} \sum_{j=1}^{n} \mathrm{X}_{\mathrm{ij}} C_{i j}+\sum_{j=1}^{n} \mathrm{O}_{\mathrm{ij}} \mathrm{S}_{\mathrm{j}}+\sum_{i=1}^{m} \sum_{j=1}^{n} d q_{\mathrm{ij}} F\left(X_{i j}\right)\right) \\
& +\mathrm{W}_{2} \max \left(\sum_{j=1}^{n} \mathrm{X}_{\mathrm{ij}} \mathrm{q}_{\mathrm{ij}}\right) \\
& \mathrm{W}_{1}+\mathrm{W}_{2}=1
\end{aligned}
$$

The proposed modal will help to make better supply order allocation by minimizing the sum of material cost (supply disruption risk) and maximizing quality, which are considered simultaneously but are weighted according to their relative importance. 


\section{CONCLUSION}

Order allocation is one of the most important decisionmaking problems. In real situations, it is a multiple criteria decision-making problem in which the objectives and the constraints are not equally important. Penalty functions was developed for solving the problem of order allocation. Thus, the proposed model in this paper can help the users to choose the appropriate order allocation.

However, this research still has many points that should be further studied. For example, material reserve quantities in company are important to allocate order among supplier. We hope that future model can joint this aspect.

\section{ACKNOWLEDGMENT}

This work is partially supported by grants from the National Natural Science Foundation of China (NSFC nos. U1333115, 71373188, 90924024, 91224001, 71231007 and 71101060) and, the Fundamental Research Funds for the Central Universities (No.1101012), Post-1970 Young Scholars in Humanities and Social Sciences from Wuhan University, Training Program of High Level International Journal Articles in Humanities and Social Sciences from Wuhan University.

\section{REFERENCES}

[1] Arief Adhitya, Rajagopalan Srinivasan, I.A. Karimi, A model-based rescheduling framework for managing abnormal supply chain events, Computers and Chemical Engineering xxx (2006) xxx-xxx.

[2] A.C. Pan, Allocation of order quantity among suppliers, Journal of Purchasing and Materials Management 25 (3)(1989) 36-39.

[3] A. Ghobadian, A. Stainer, T. Kiss, A computerized vendor rating system, Proceedings of the First International Symposium on Logistics, The University of Nottingham, Nottingham,UK, July 1993, pp. 321-328.

[4] A. Hammami, P. Burlat, J.P. Campagne, Evaluating orders allocation within networks of firms, Int. J. Production Economics 86 (2003) 233 249.

[5] Basnet C, Leung JMY, Inventory lot-sizing with supplier selection, Computers and Operations Research 2005;32:1-14.

[6] Buffa FP, Jackson WM, A goal programming model for purchase planning., Journal of Purchasing and Materials Management 1983;19:2734.

[7] B.G. Kingsman , Purchasing raw materials with uncertain fluctuating prices, European Journal of Operational Research 25(1986) 358-372.

[8] C.A. Weber, J.R. Current, W.C. Benton, Vendor selection criteria and methods, European Journal of Operational Research 50 (1991) 2-18.

[9] Chen, I.J., \& Paulraj, A., Understanding supply chain management: critical research and a theoretical framework. International Journal of Production Research, 42(2004), 131-163.

[10] Chun-ling chuang, Supplier selection and order allocation in supply chain management, the Graduate college of the university of Iowa ,(May 2004)80-102.

[11] Christopher S. Tang, Perspectives in supply chain risk management, Int J. Production Economics 103(2006) 451-488.

[12] DO BA KHANG and OKITSUGU FUJIWARA, OPTIMALITY OF MYOPIC ORDERING POLICIES FOR INVENTORY MODEL WITH STOCHASTIC SUPPLY, Operations Research, Vol. 48, No. 1, JanuaryFebruary 2000, pp.181-184.

[13] Ezgi Aktar Demirtas, Öden üstün, An integrated multiobjective decision making process for supplier selection and order allocation, Omega (www.elsevier.com/locate/omega).

[14] Felix T.S. Chan - S.H. Chung - K.L. Choy, Optimization of order fulfillment in distribution network problems ,J Intel Manuf (2006) 17:307-319.
[15] Harvey E. Lapan, David A, Hennessy Symmetry and order in the portfolio allocation problem, Economic Theory 19, 747-772 (2002)

[16] I. Turner, An independent system for the evaluation of contract tenders, Operational Research Society 39 (6) (1988) 551-561.

[17] Peter Kelle, Pam Anders Miller, Stockout risk and order splitting, Int. J. Production Economics 71(2001) 407-415.

[18] Roshan Gaonkar, N. Viswanadham, A Conceptual and Analytical Framework for the Management of Risk in Supply Chains, Proceeding of the 2004 IEEE international Conference on Robotics \& Automation, New Orleans, LA, April 2004.

[19] Ruengsak Kawtummachai, Nguyen Van Hop, Order allocation in a multiple-supplier environment, Int. J. Production Economics 93-94 (2005) 231-238

[20] R. Narasimhan, K. Stoynoff , Optimizing aggregate procurement allocation decisions, Journal of Purchasing and Materials Management 22 (1) (1986) 23-30.

[21] S.H. Ghodsypour , C. O'Brien, The total cost of logistics in supplier selection, under conditions of multiple sourcing, multiple criteria and capacity constraint, Int. J. Production Economics 73 (2001) 15-27.

[22] Schmidt, G.,\&Wilhelm, W.E, Strategic, tactical and operational decisions in multi-national logistics networks: A review and discussion of modeling issues. International Journal of Production Research, 38(2000), 1501-1523.

[23] SYAM MENON, LINUS SCHRAGE, ORDER ALLOCATION FOR STOCK CUTTING IN. THE PAPER INDUSTRY, Operations Research ,Vol. 50, No. 2, March-April 2002, pp. 324-332.

[24] Sohail S Chaudhry, Frank G. Forst, James L Zydiak, A Multicriteria Approach to Allocating Order Quantity Among Vendors, Production and Inventory Management Journal, Third Quarter 1991; 32, 3; ABI/INFORM Global pg. 82.

[25] Shitao Yanga,, Jian Yangb, Layek Abdel-Malek, Sourcing with random yields and stochastic demand: A newsvendor approach, Computers \& Operations Research (www.elsevier.com/locate/cor).

[26] Vaidyanathan Jayaraman, Rajesh Srivastava, W C Benton ,Supplier selection and order quantity allocation: A comprehensive model, Journal of Supply Chain Management; Spring 1999; 35, 2; ABI/INFORM Global pg. 50

[27] Vollmann TE, Berry WL Whybark DC, Jacobs FR, Manufacturing planning and control systems for supply chain management. 5th ed., Boston:Irwin/McGraw-Hill; 2005.

[28] Xiaoming Lia, V. Sridharan, Characterizing order processes of using ( $R$, nQ) inventory policies. in supply chains, Omega.

[29] Xiangtong Qi ,Order splitting with multiple capacitated suppliers, European Journal of Operational Research xxx (2006) xxx-xxx. 